\title{
The Influence of Solvent on the Solvolysis of Ethyl Cinnamate in Water Acetone Mixed Solvent System
}

\author{
A.K. Singh \\ Department of Chemistry \\ Teerthanker Mahaveer University, Moradabad, India.
}

\begin{abstract}
The kinetic of alkaline hydrolysis of Ethyl Cinnamate was investigated at different percentage of aqua-organic solvent mixture with Acetone (30 to $70 \%$ v/v) over the temperature range of 200

C to 40 o $\mathrm{C}$. The specific rate constant was found to be decreased with increasing proportion of solvent (Acetone) at all the temperature range. The Iso-composition Activation energy (EC) was also evaluated which decreases with solvent composition in (waterAcetone) system. The number of water molecule associated with the activated complex is found to be increase $(0.7003$ to 0.786$)$ in waterAcetone system. The Thermodynamic Activation Parameter such as Enthalpy of Activation ( $\left.\square H^{*}\right)$, Entropy of Activation ( $\left.\square S^{*}\right)$ and Gibb's free energy of activation $\left(\square G^{*}\right)$ were also calculated.
\end{abstract}

Keywords-Solvolysis; Solvent-solute interaction; Iso composition Energy; Activated complex; Activation parameters.

\section{INTRODUCTION}

Although the solvent effect on the rate and mechanism of the various type of reaction has been reported [1-3] but very little attention has paid towards the study of the solvent effect on the Thermodynamic Activation Parameter and the solvent-solute interaction, particularly for an ion-dipolar reaction. In order to highlight the above noted idea, it has been proposed to make the kinetic study of the solvent effect on the alkali catalyzed hydrolysis of ethyl Cinnamate.

\section{EXPERIMENTAL}

All the chemical used were either of BDH (Analar) or Merck (CD) grades. The water used was doubly distilled. The specific rate constant value was calculated using second order reaction and tabulated in Table-I \& II the Iso composition Activation energy (EC) were evaluated and tabulated in Table-III. The number of water molecule evaluated by the slope of plot of $\operatorname{logk}$ and $\log (\mathrm{H} 2 \mathrm{O})$ and inserted in Table-V. Thermodynamic Activation Parameter was also calculated inserted in Table VI.

\section{RESULT AND DisCUSSION}

\section{A. Solvent Effect on Rate of Reaction}

From table I\&II (Fig. 1), it is clear that specific rate constant values of the reaction go on decreasing with increasing organic co-solvent in the solvent (Acetone). From the plot of logk with mole\% of organic co-solvent, it was observed that plots follows trend at all temperature. From the plot (Fig. 1) it is also apparent that the decrease is regular and follows linear trend at all the temperature in solvent. The trend of variation in the values of specific rate constant may be discuss in light of the Hughes and Ingold [4] theory. According to the theory of increase in dielectric constant values of the reaction media result in increase in the rate when there is concentration of charges on the transition state and cause a decrease in the rate when there is diffusion or destruction of charges on transition state. Acetone being poor anion solvater their increase in aqueous medium will facilitate the desolvation of ions already solvated by water molecule. Since initial and transition state (both being anions differing in size and charge) cannot be equally desolated, the rate will be affected by such specific salvation changes. Depletion in the rate of the reaction in different reaction with change temputcture and constants of acetone of reaction media portly partly due to dielectric effect and partly due to salvation change to different degree in the initial and translated of reaction. Our interpretation has also been supported recently by Singh A. K. [5]. 
TABLE - I

Specific rate constant $\left.\mathrm{k} \times 10^{3}(\mathrm{dm})^{3} / \mathrm{mole} / \mathrm{mint}\right]$ values of alkali catalyzed Hydrolysis of Ethyl-Cinamate in water-Acetone

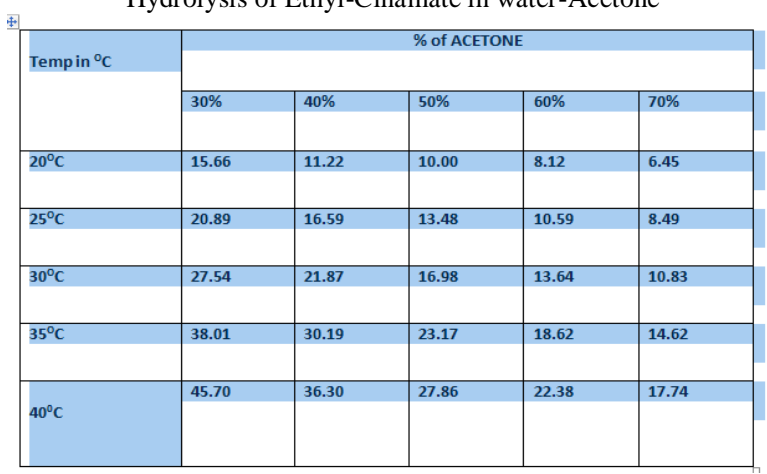

TABLE - II

variation $3+$ Logk Value against $10^{3} / \mathrm{T}$, Water- Acetone System.

\begin{tabular}{|c|c|c|c|c|c|c|}
\hline \multirow{2}{*}{ Temp in ${ }^{\circ} \mathrm{C}$} & & \multicolumn{5}{|c}{$3+$ Logk } \\
& & \multicolumn{5}{|c}{} \\
\cline { 2 - 7 } & $10^{3} / \mathrm{T}$ & $30 \%$ & $40 \%$ & $50 \%$ & $60 \%$ & $70 \%$ \\
\hline $20^{\circ} \mathrm{C}$ & 3.412 & 1.195 & 1.095 & 1.000 & 0.910 & 0.810 \\
\hline $25{ }^{\circ} \mathrm{C}$ & 3.355 & 1.320 & 1.220 & 1.130 & 1.025 & 0.929 \\
& & & & & & \\
\hline $30^{\circ} \mathrm{C}$ & 3.300 & 1.440 & 1.340 & 1.230 & 1.135 & 1.035 \\
& & & & & & \\
\hline $35^{\circ} \mathrm{C}$ & 3.247 & 1.580 & 1.480 & 1.365 & 1.27 & 1.165 \\
& & & & & & \\
\hline $40^{\circ} \mathrm{C}$ & 3.195 & 1.665 & 1.560 & 1.445 & 1.350 & 1.249 \\
& & & & & & \\
\hline
\end{tabular}

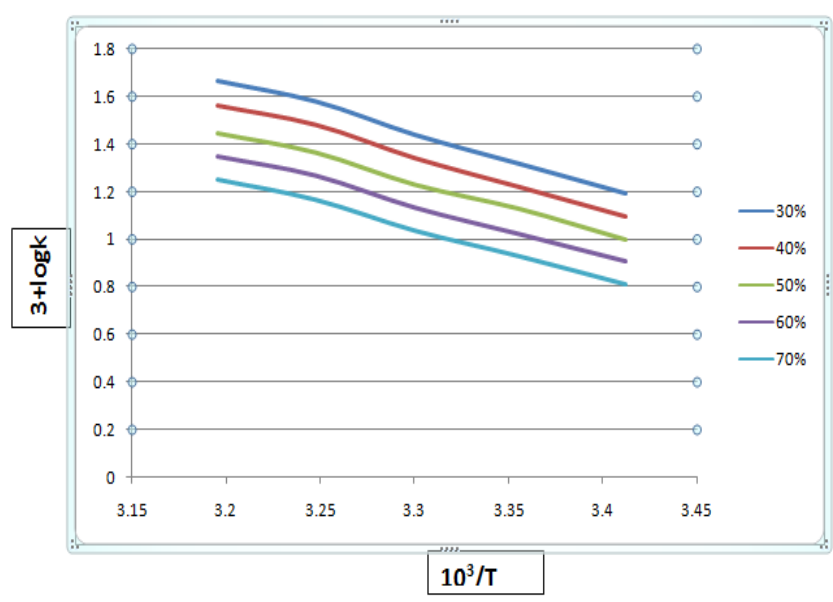

Fig.1: Variation of $3+\log K$ value with $10^{3} / T$ (water-Acetone media)

\section{B Effect of Solvent on Activation Energy (Iso-composition) of the reaction}

From Tab III and fig-2, it is found that the value of Isocomposition Activation Energy is goes on decreasing trend with gradual addition of organic content In case of Acetone the value of Activation Energy decrease from 41.64 to $37.39 \mathrm{Kj} / \mathrm{mole}$ with increase proportion of Acetone in water-acetone media.

The depleting trend in the $\mathrm{E}_{\text {exp }}$ values can be explained by any of the following three situations.

(i) The transition state is less desolvated than the initial state.

(ii) The initial state is less solvated than the transition state.

(iii) The initial state is desolvated and the transition state is solvated.

Out of three situation the third factor seems to be operative as both $\square \mathrm{H}^{*}$ and $\square \mathrm{S}^{*}$ values of the reaction were found with decreasing with increasing concentration acetone in waterAcetone media. Our this inference has also been in favors of the finding of Singh A. K. [5].

On the basis of depletion (water-Acetone) media, it is inferred that acetone has the solvating power to solvate the initial state and to desolated the transition state. Our this finding is also supported by Singh A K [6].

TABLE - 111

Values of Iso-composition Activation Energy (water-Acetone ) media

\begin{tabular}{|l|l|l|l|l|l|}
\hline \% of ME-OH & $30 \%$ & $40 \%$ & $50 \%$ & $60 \%$ & $70 \%$ \\
\hline $\begin{array}{l}\text { Sexp }_{\mathrm{K} / \mathrm{mole}} \text { in } \\
\mathrm{KJ}\end{array}$ & 41.64 & 41.28 & 39.81 & 38.73 & 37.39 \\
\hline
\end{tabular}


C. Effect of solvating power on the number of water molecules associated with the Activated complex and on mechanistic path of the reaction

The effect of water concentration $\left[\mathrm{H}_{2} \mathrm{O}\right]$ of water-Acetone media on rate and mechanism of alkaline hydrolysis of ethyl cinnamate has been studied in light of guideline and observation render by Tommil-E [7] Lane-C.A.[8] Elsmongy et al[9] they have established an idea of the number of water molecule associated with the Activated complex has been determined by plotting logk against by $\left[\mathrm{H}_{2} \mathrm{O}\right]$.According to the relation proposed by Robertson[10].

$$
\operatorname{logk}=\log _{0}+\mathrm{n} \log \left[\mathrm{H}_{2} \mathrm{O}\right]
$$

Here, $\mathrm{n}$ is the salvation number which tells about the criteria for studying about the mechanism of reaction.

It is obvious from the plots of $\operatorname{logk}$ versus $\log \left[\mathrm{H}_{2} \mathrm{O}\right]$ that at all the five temperature at which kinetics were studied, straight lines fig-2 From the value of slope as mention table-V, (Fig.2) the number of water molecules associated with Activated complex varies from (0.700to 0.786) in case of water-Acetone media with rise of temperature.

From the above values of slope mention in table III it is inferred that equilibrium shifted from dense form (d) of water to bulk form (b) in case of water-Acetone media, with rise of temperature.

$$
\left[\mathrm{H}_{2} \mathrm{O}\right]_{\mathrm{d}} \leftrightarrows\left[\mathrm{H}_{2} \mathrm{O}\right]_{\mathrm{b}}
$$

In the light of finding of Robertson [10] and .Singh A K.[11] and from above noted trend, it is concluded that solvating power of Acetone change the mechanism of the reaction from biomolecular to unimolecular, The resent report of Singh A $\mathrm{K}[12]$ has been support of our finding

Table-IV

\begin{tabular}{|c|c|c|c|c|c|c|c|}
\hline \multirow{2}{*}{$\begin{array}{l}\% \text { of } \\
\text { Acetone }\end{array}$} & \multirow{2}{*}{$\begin{array}{l}\% \\
\mathrm{H}_{2} \mathrm{O}\end{array}$} & \multirow{2}{*}{$\begin{array}{l}\mathrm{Log} \\
{\left[\mathrm{H}_{2} \mathrm{O}\right]}\end{array}$} & \multicolumn{5}{|c|}{$3+\log k$} \\
\hline & & & $20^{\circ} \mathrm{c}$ & $25^{\circ} \mathrm{c}$ & $30^{\circ} \mathrm{c}$ & $35^{\circ} \mathrm{c}$ & $40^{\circ} \mathrm{c}$ \\
\hline $30 \%$ & $70 \%$ & 1.5690 & 1.170 & 1.260 & 1.440 & 1.520 & 1.642 \\
\hline $40 \%$ & $60 \%$ & 1.5229 & 1.130 & 1.220 & 1.3360 & 1.470 & 1.590 \\
\hline $50 \%$ & $50 \%$ & 1.4437 & 1.030 & 1.140 & 1.280 & 1.390 & 1.510 \\
\hline $60 \%$ & $40 \%$ & 1.3468 & 0.940 & 1.050 & 1.180 & 1.300 & 1.140 \\
\hline $70 \%$ & $30 \%$ & 1.2218 & 0.820 & 0.920 & 1.060 & 1.170 & 1.280 \\
\hline
\end{tabular}

Variation of 3+ $\log \mathrm{k}$ with $\log \left[\mathrm{H}_{2} \mathrm{O}\right]$ (water - Acetone) at different temperature

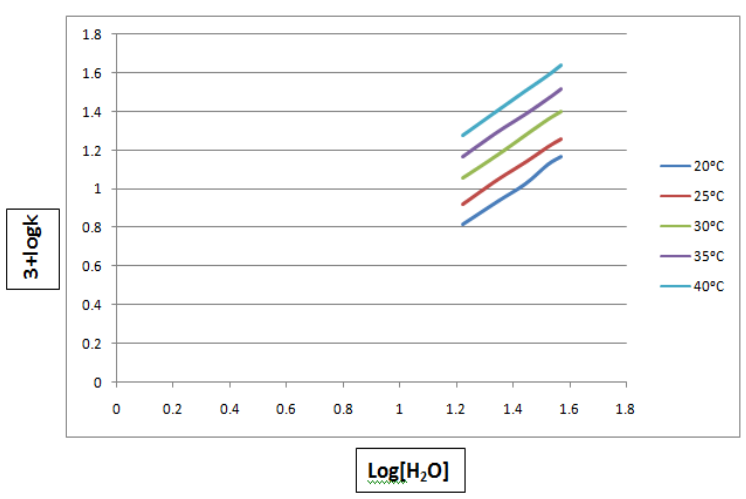

Fig.2: Variation of $3+$ logk value with $\log \left[\mathrm{H}_{2} \mathrm{O}\right]$ (water-Acetone media)

Table-V

The value of slope of plot of $\log \mathrm{k}$ verses $\log \left[\mathrm{H}_{2} \mathrm{O}\right]$ of reaction in water-Acetone media

\begin{tabular}{|l|l|l|l|l|l|}
\hline Temp ${ }^{0} \mathrm{C}$ & $20^{\circ} \mathrm{c}$ & $25^{0} \mathrm{c}$ & $30^{\circ} \mathrm{c}$ & $35^{0} \mathrm{c}$ & $40^{\circ} \mathrm{c}$ \\
\hline Slope & 0.700 & 0.732 & 0.746 & 0.759 & 0.786 \\
\hline
\end{tabular}

\section{D.Thermodynamic Activation Parameters}

Table-VI

Thermodynamics Activation Parameters of the Reaction in Water- Acetone Media ( $\Delta \mathrm{H}^{*}$ and $\Delta \mathrm{G}^{*}$ in $\mathrm{KJ} /$ Mole, $\Delta \mathrm{S}^{*}$ in $\mathrm{J} / \mathrm{K} /$ Mole)

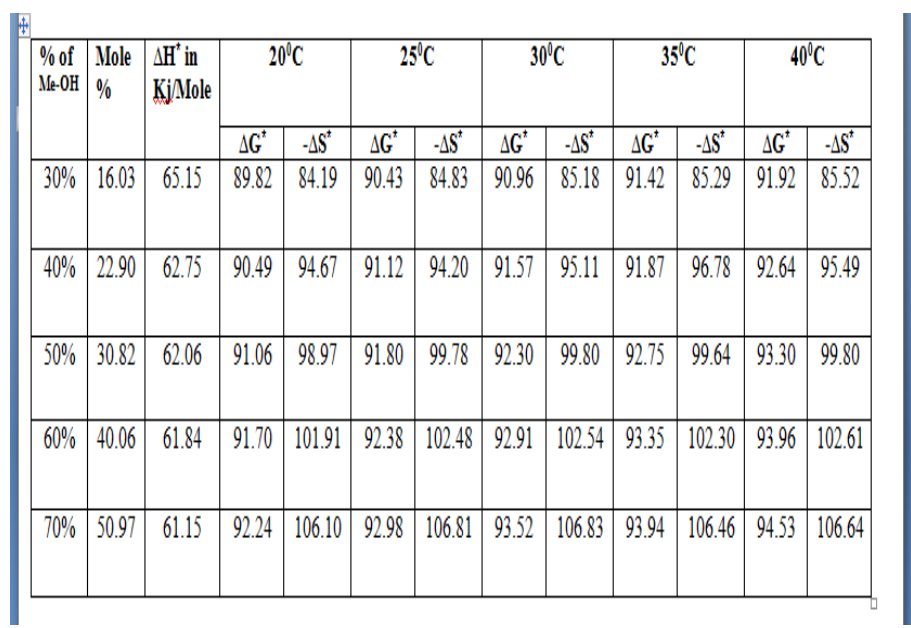

\section{CONCLUSION}

The result of this work indicate that the rate of hydrolysis of Ethyl cinnamate decreasing trend at all temp which appear that depletion in rate of reaction with change in temperature and concentration is probably due to dielectric effect and partly due to salvation change to different degree in transition state of reaction. Decrease in value of activation energy with gradual increasing proportion of acetone indicates that initial state is desolveted and transition state is solvated. The number of water 
molecule associated with Activated complex indicates the solvating power of acetone change the mechanism of reaction from bimolecular to unimolecular.

\section{ACKNOWLEDGMENT}

My special gratitude to my supervisor Prof. R T Singh for his proper guidance and thanks to my friend Dr Ajit and Mr. L K Tiwari Dr. parag for his cooperation during preparation of this content. I am Thankful to Mrs. Rolly Gupta \& Miss Akansha Singh for typing assistance.

\section{REFERENCES}

[1] Singh A.K, "A Kinetics Study of Solvent Effect on Thermodynamics Activation Parameter on alkali catalyzed Solvolysis of Methyl Saliccylate in water-DMF Media". Inter. Jounrnal of Adv. Research and Innovation .Vol-3, Issue -3, 2015 PP. 547-549

[2] Magda F. Fathalla, "Kinetics of Reaction of 2-Chloro-quinoxaline with Hydroxide Ion in CAN-H2 O and DMSO-H2O Binary Solvent Mixture", J. Solution Chem., 2011, 40, 1258-70,

[3] Singh. A.K," Solvent Effect On Solvolysis Rate in Alkalaline Hydrolysis of Ethyl Acetate in water-methanol and water-ethanol mixed solvent system”. Inter. J.for Res. In Applied Science \& Engg. Tech. (IJRASET), Vol.-4, Issue-IX., Sep2016, pp 505-509.

[4] Hughes E.D. and Ingold C.K, " Mechanism of substitution at saturated carbon atom part IV, A discussion of constitution and solvent effect on mechanism, kinetics, velocity, and orientation of substitution". j chem. Soc 1935, 244- 255.

[5] Singh A K," Solvolysis rate and activation parameter of Ethyl acetate in mixed dipolar organic solvent systems-A Solvent effect". . Inter. J.for Res. In Applied Science \& Engg. Tech. (IJRASET), Vol.-4, Issue-X, Oct 2016 pp. 706-709.

[6] Singh. A.K, "A kinetics study of solvent effect on solvent-solute interaction and mechanism of the Ion dipolar reaction in an aquoorganic co-solvent system,' Inter. J.for Res. In Applied Science \& Engg. Tech. (IJRASET), Vol.-3, Issue-I, Jan2015 .pp.164-168.

[7] Tommila E. paakhala E, U.K. Virtanen, Ann. Acad. Sci. Fennec A II, 91, 1959,

[8] C.A. Lane, "The possibility of cyclic mechanism of Acid catalyzed ester hydrolysis. J. Am. chem. soc. 86, 1964 pp. 2521-2523.

[9] M.M. ElsemongyAbu, Elamayn, M S and Moussa: Z. phys. chem. 84, 1973,294

[10] R.E. Robertson, "A survey of thermodynamic parameter for solvolysis in water", Prog. Phy.Org. chem.. 4, 1967 pp213

[11] Singh. A.K," A kinetics study of solvent effect on solvent-solute interaction and mechanism of the Ion dipolar reaction in an aquoorganic co-solvent system”, Inter. J.for Res. In Applied Science \& Engg. Tech. (IJRASET), Vol.-3, Issue-I, Jan2015 .pp164-168.

[12] Singh. A.K," A kinetics study of solvent effect on solvent-solute interaction and mechanism of the ion dipolar reaction in aquo organic co solvent system". Inter. J.for Res. In Applied Science \& Engg. Tech. (IJRASET), Vol.-3, Issue-I, 2015 .pp164-168.

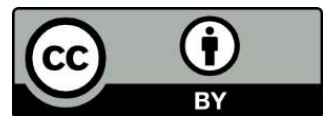

(C) 2017 by the author(s); licensee Empirical Research Press Ltd. United Kingdom. This is an open access article distributed under the terms and conditions of the Creative Commons by Attribution (CC-BY) license. (http://creativecommons.org/licenses/by/4.0/). 